\title{
Surgical management of intracapsular fracture neck femur by hemiarthroplasty between uncemented bipolar prosthesis and Austin Moore's prosthesis: a comparative study in elderly population
}

\author{
H. D. Veeranna, K. B. Ravi*, K. Anudeep Kumar
}

Department of Orthopaedics, Sri Siddhartha Medical College, Siddhartha Academy of Higher Education University, Tumkur, Karnataka, India

Received: 09 May 2019

Revised: 29 May 2019

Accepted: 30 May 2019

*Correspondence:

Dr. K. B. Ravi,

E-mail: drnokb@gmail.com

Copyright: ( $)$ the author(s), publisher and licensee Medip Academy. This is an open-access article distributed under the terms of the Creative Commons Attribution Non-Commercial License, which permits unrestricted non-commercial use, distribution, and reproduction in any medium, provided the original work is properly cited.

\begin{abstract}
Background: Intracapsular femoral neck fractures are common in elderly population after a simple fall. To avoid the drawbacks of internal fixation and for the early mobilization, hemiarthroplasty is performed in elderly. The aim of this study is to compare the outcome AMP with uncemented bipolar prosthesis in geriatric patients.

Methods: 51 patients above 60 years and an acute displaced fracture of the femoral neck were randomly allocated to treatment by either AMP (Austin Moore prosthesis) or bipolar hemiarthroplasty, in the Department of Orthopaedics, Sri Siddhartha medical college, Tumkur between April 2014 and May 2017. The patients were summoned at 6 weeks, 12 weeks, 6 months and 1 year. Functional outcome was assessed and compared with modified Harris hip score and radiological parameters.

Results: The mean Harris hip score in bipolar and AMP group was $86.31 \pm 12.1$ and $79.86 \pm 15.42$, respectively $(\mathrm{p}=0.182)$. The range of motion was $204.52 \pm 28.2$ and $183.62 \pm 36(\mathrm{p}=0.014)$ respectively. Functional activities like use of public transport and ability to wear shoe or socks was better with bipolar group. Incidence of complications like painful hip, posterior dislocation, periprosthetic fracture and acetabular erosion was encountered in AMP group.

Conclusions: The use of uncemented bipolar endoprosthesis in the management of displaced femoral neck fractures in the elderly was associated with better mean Harris hip score and incidence of complications was limited. Hence, bipolar would be a better option in elderly patients with fracture neck of femur.
\end{abstract}

Keywords: Unipolar, Bipolar, AMP, Hemiarthroplasty, Femur neck fracture

\section{INTRODUCTION}

A fracture of the hip is a common injury. With increasing life expectancy throughout the world, the number of elderly individuals is increasing in every geographical area, and it is estimated that incidence of hip fracture will rise from 1.56 million in 1990 to 6.38 million by 2045 . Intracapsular femoral neck fractures can be divided into displaced and undisplaced fractures. According to the Swedish national hip fracture register, intracapsular fractures of femoral neck constitute $53 \%$ of all hip fractures out of which $33 \%$ is undisplaced and $67 \%$ is displaced. ${ }^{1}$

The rationale for operative treatment by means of internal fixation is to reduce the risk of secondary displacement of undisplaced fractures, and to maintain fracture reduction in displaced fractures. The main reasons for failing of internal fixation are avascular necrosis and non-union. Failure of internal fixation lead to a reintervention rate of 
$35 \%$ with decreased function and increased morbidity as demonstrated by a meta-analysis done by Yao. ${ }^{2}$

Replacement of the femoral head and neck with prosthesis offers a way to prevent all possible complications of internal fixation and is therefore a better alternative in a biologically elderly patient. There is however no consensuses how to treat patients with a displaced intracapsular fracture between sixty and eighty years old. It is therefore and because of poor clinical results that the displaced intracapsular fracture is referred to as the unsolved fracture. ${ }^{3,4}$

The first hemiarthroplasty was introduced in 1940 by Moore and Bohlman, after removal of giant cell tumour of the femoral head. ${ }^{5,6}$

\section{Aims and objectives of the study}

This study was undertaken to compare the results of uncemented bipolar prosthesis and Austin Moore's prosthesis in the management of fracture neck femur in elderly population with reference to

- The quality of life after hemiarthroplasty between the two groups,

- Hospitalization and mobilization time between the two prosthesis group and mortality rate difference,

- The recovery of physical, social and vocational independence and rehabilitation in both the groups,

- The radiographic changes in the two groups,

- The complications of the surgery, including painful hip, stem loosening, infections, acetabular erosions, prosthetic migration, range of movements and prosthetic removal between the two groups.

The following is a comparative clinical study presenting the short-term results of randomized prospective study of uncemented hemiarthroplasty using bipolar prosthesis and Austin Moore's prosthesis. Functional outcome at 6 weeks, 3 months, 6 months and 1 year were analyzed and compared using modified Harris hip score and radiographs.

\section{METHODS}

The present study of 51 cases of intracapsular fracture neck of femur in elderly patients above the age of 60 years irrespective of sex treated by hemiarthroplasty using unipolar (Austin Moore's) or uncemented bipolar prosthesis, was done in the Sri Siddhartha hospital, sri Siddhartha Medical College and Research Centre, B.H. Road, Agalkote, Tumkur, Karnataka, selected on the basis of purposive sampling (judgment sampling) method. The study period was from April 2014 to May 2017. The clearance has been obtained by the ethical committee.

\section{Inclusion criteria}

Case of fracture neck femur of age group above 60 years; all patients medically fit for surgery even with hypertension and diabetes mellitus; All types of fractures under Gardens classification are considered; closed fractures; fracture within 20 days and pre-injury ambulatory patients.

\section{Exclusion criteria}

Terminally ill patients and patients unfit for surgery; pathological fracture; compound fracture; other limb fractures and neurovascular injuries.

In this study primary hemi replacement arthroplasty of hip is done in 51 cases of fracture neck of femur, using uncemented bipolar prosthesis for 25 cases and Austin Moore's prosthesis for 26 cases. The operative procedure is meticulously followed; the results are evaluated and compared.

An anteroposterior radiograph of the pelvis with both hip joints is taken for all the patients on admission. Routine blood investigations RBS, serum urea, creatinine, chest $\mathrm{x}$ ray, ECG and 2D echocardiography were done and medical fitness were taken for surgery. Patients as well as attendees were explained about the surgery and its risk factors and written and informed consent for surgery was taken.

\section{Surgical procedure}

All the surgeries were performed on an elective basis using standard aseptic precautions with spinal, epidural or general anaesthesia. Lateral position with the patient lying on unaffected side. The lower extremity from the groin to toes was draped in sterile towels separately to enable easy manipulation of the limb during surgery. For all patients postero lateral approach (Moore's Approach) was used in our series.

The fractured head and neck of the femur is levered out of the acetabulum and head size is measured using femoral head gauge. The acetabulum was prepared by excising any soft tissues. The femoral canal was rasped using a broach (rasp) and prepared for insertion of the prosthesis. The prosthesis was then inserted into the femoral shaft in about 5-10 degrees of anteversion and impacted into the femur. No bone cement was used for the cases. The reduction of the prosthesis was then done with gentle traction of the thigh. Wound was closed in layers over a suction drain, which was removed at the first dressing change after 48 hours.

\section{Postoperative management}

IV fluids given, after 6 hours oral fluids are given. Intravenous antibiotics and analgesics were continued for 7 days post operatively. Both the lower limbs are kept in 
abduction with a pillow in between both the legs. Check radiographs were taken after 48 hours. Patients were made to sit up on the second day, stand-up with support (using walker), on the third day, and were allowed to full weight bear and walk with help of a walker on the fourth postoperative day depending on the pain tolerance. Sitting cross-legged and squatting were not allowed.

Suture removal was done on the thirteenth $\left(13^{\text {th }}\right)$ postoperative day. The patients were assessed for any shortening or deformities if any and discharged from the hospital. Patients who had infection and bedsores were treated accordingly before discharging from the hospital.

\section{Follow up}

Patients were followed up at an interval of 6 weeks, 3 months, 6 months and one year. Functional assessment was analyzed by modified Harris hip scoring system for pain, limp, the use of support, walking distance, ability to climb stairs, ability to put on shoes and socks, sitting on a chair, ability to enter public transportation, deformities, leg length discrepancy and movements were recorded in the follow up chart. At each follow up, radiograph of the hip was taken for radiological analysis.

\section{Harris hip scoring system}

The HHS was developed for the assessment of the results of hip surgery, and is intended to evaluate various hip disabilities and methods of treatment in an adult population. The original version was published $1969 .^{7}$

Total functional outcome was graded as following depending on the total Harris:

- Failure: Harris hip less than 60

- Poor: Harris hip score between 60-69

- Fair: Harris hip score between 70-79

- Good: Harris hip score between 80-89

- Excellent: Harris hip score between 90-100

The functional outcomes of the groups were then compared.

\section{Statistical methods}

Descriptive and inferential statistical analysis has been carried out in the present study. Results on continuous measurements are presented on Mean \pm SD (min-max) and results on categorical measurements are presented in number (\%). Significance is assessed at 5\% level of significance. Following assumptions are made: 1 Dependent variables should be normally distributed. 2 . Samples drawn from the population should be random. Cases of the samples should be independent.

Student $\mathrm{t}$ test (two tailed, independent) has been used to find the significance of study parameters on continuous scale between the two groups (inter group analysis) on metric parameters. Chi-square/ Fisher Exact test has been used to find the significance of study parameters on categorical scale between two or more groups. ${ }^{8}$

The assumptions of Chi-square test is as follows. ${ }^{9-11}$

Random sample: A random sampling of the data from a fixed distribution or population

Sample size: A sample with a sufficiently large size is assumed. If chi square test is conducted on a small sample size, then the test will yield an inaccurate inference. The researcher, by using chi square test on small samples, might end up committing a type 2 error.

Association between two qualitative variables was seen by using Chi square/Fischer's exact test. Comparison of mean and Standard Deviation between two groups was done by using unpaired t test to assess whether the mean difference between the groups is significant or not. A p value of $<0.05$ was considered as statistically significant whereas a $\mathrm{p}<0.001$ was considered as highly significant.

Statistical software: The statistical software namely SAS 9.2, SPSS 15.0, Stats 10.1, MedCalc 9.0.1, System 12.0 and R environment ver. 2.11.1 were used for the analysis of the data and Microsoft word and Excel have been used to generate graphs and tables.

\section{RESULTS}

\section{Distribution of patients}

Of the 51 cases, 25 cases were managed with bipolar prosthesis and 26 cases with Austin Moore's prosthesis.

The following observations were made from the data collected during the study.

\section{Age distribution}

In our study among 51 cases, maximum age recorded in both the male and female patients was 86 years. Most of the patients were in the age group of 60-70. The mean age in bipolar group was 65.2 years and AMP group was 73.55 (Table 1).

\section{Sex distribution}

Of the 51 cases, 22 cases were male and the rest 29 were females. In bipolar group, 12 male cases and 13 female cases were recorded whereas in AMP group, 10 male cases and 16 female cases were present. Females constituted $56.8 \%$ of the whole cases.

\section{Side of fracture}

There were 31 cases with fracture on left side and 20 cases with fracture on the right side. $\mathrm{P}$ value was 0.73 between the two groups, suggesting statistically similarity 
between the two groups. Left side was most commonly involved in both the groups.

Table 1: Age distribution of the two groups

\begin{tabular}{|lllll|}
\hline \multirow{2}{*}{ Age in years } & \multicolumn{2}{c|}{ Group bipolar } & \multicolumn{2}{c|}{ Group AMP } \\
\cline { 2 - 5 } & No & \% & No & \% \\
\hline $\mathbf{6 0 - 7 0}$ & 17 & 68 & 9 & 34.61 \\
\hline $\mathbf{7 1 - 8 0}$ & 5 & 20 & 7 & 26.92 \\
\hline Above 80 & 3 & 12 & 10 & 38.46 \\
\hline Total & 25 & 100 & 26 & 100.0 \\
\hline Mean \pm SD & $65.2 \pm 7.48$ & $73.55 \pm 9.12$ \\
\hline
\end{tabular}

\section{Mode of injury}

Trivial fall (self fall/TT) was the most common mode of injury in both the groups (94\%). 2 cases of road traffic accident (RTA) in bipolar group and 1 case of road traffic accident in AMP group were present. Distribution of mode of injury is statistically similar in the two groups with $\mathrm{p}=0.49$.

\section{Type of fracture: Garden's classification}

All the fracture types were classified with Gardens classification. There were 9 cases each with gardens type $2(35.3 \%)$. But in Bipolar group, garden type 2 injury was encountered in $36 \%$ of the cases whereas in AMP group garden type 3 were most commonly present. Distribution of Garden type of injury was statistically similar in the two groups with $\mathrm{p}=0.825$.

\section{Mortality}

Among 51 patients, 8 patients $(15.6 \%)$ expired during the follow up period due to other co morbidities, among them 4 patients from each of the group died. Bipolar (16\%) and AMP (15.38\%) mortality rate was statistically similar in both of the groups (with $\mathrm{p}=0.65$ ).

\section{Assessment of functional results}

The patients were followed up at 6 weeks, 3 months, 6 months and 1 year. Using modified Harris hip-scoring system, the functional results of hemiarthroplasty was assessed. The results of the final follow up, that is 1 year was considered for our analysis. Assessment was done with the following criteria.

1. Pain, 2. Limp, 3 use of support, 4 walking distance, 5 climbing of the stairs, 6 put on shoes and socks, 7 sitting on chair, 8 enter public transport, 9 deformities, 10 leg length discrepancy, 11 range of motion.

\section{Pain}

The patients were enquired about the kind of pain they experienced during their daily activity and recorded according to the grade and scores. No pain was present in the $57.14 \%$ of the patients of bipolar group and $36.36 \%$ for the AMP group. 2 case of AMP group has experienced marked pain. Distribution of pain is statistically similar in both the groups with $\mathrm{p}=0.225$.

\section{Limp}

In our study all the patients were observed for their gait and noted for their limp and recorded. 57.14\% in bipolar and 50\% in AMP group had no limp. Distribution of limp is statistically similar in both the groups with $\mathrm{p}=0.57$.

\section{Use of support}

In our study, $40.9 \%$ of AMP group used no support for walking whereas $38.09 \%$ of the patients with bipolar group used cane only for walking long distances. None of the cases used two canes or crutches. Distribution of support system is statistically similar in both the groups with $\mathrm{p}=0.72$.

\section{Distribution of public transport use of the patients studied}

$76.19 \%$ of bipolar group were able to use the public transport compared to only $54.54 \%$ the patients of the AMP group, suggesting a significant statistical difference in the two groups $(\mathrm{p}=0.072)$ (Table 2).

Table 2: Use of public transport by the study groups.

\begin{tabular}{|lllll|}
\hline Public & \multicolumn{2}{c|}{ Group bipolar } & \multicolumn{2}{c|}{ Group AMP } \\
\hline transport & No & $\%$ & No & $\%$ \\
\hline No & 5 & 23.80 & 10 & 45.45 \\
\hline Yes & 16 & 76.19 & 12 & 54.54 \\
\hline Total & 21 & 100.0 & 22 & 100.0 \\
\hline
\end{tabular}

\section{Ability to wear shoe or socks (cut toe nail)}

$57.14 \%$ of bipolar group were able to wear shoe and socks with difficulty whereas $72.72 \%$ of AMP group had difficulty in wearing shoe and socks. Wear shoe and socks easy is significantly more associated with group Bipolar with $\mathrm{p}=0.041^{*}$ (Table 3$)$.

Table 3: Ability to wear shoe and socks by the study groups

\begin{tabular}{|lllll|}
\hline Wear shoe and & \multicolumn{2}{c|}{ Group bipolar } & \multicolumn{2}{c|}{ Group AMP } \\
\cline { 2 - 5 } socks & No & \% & No & \% \\
\hline With easy & 9 & 42.85 & 4 & 18.18 \\
\hline With difficulty & 12 & 57.14 & 16 & 72.72 \\
\hline Unable & 0 & 0.0 & 2 & 9.09 \\
\hline Total & 21 & 100.0 & 22 & 100.0 \\
\hline
\end{tabular}

\section{Range of movements}

In all the patients, sum of all the existing range of movements were recorded and graded. Mean range of 
movements was 208.5 in bipolar and 179.3 in AMP group. ROM is significantly more in patients with bipolar with $\mathrm{p}=0.014^{*}$.

\section{Harris hip score}

All the functional scorings were summed and graded as below. Mean HHS is statistically more with patients of Bipolar that is 86.31 compared to 79.86 in AMP group. The distribution of results signifies, there is no statistical difference between the two groups, $\mathrm{p}=0.256$ (Table 4).

Table 4: Harris hip scores of the two study groups.

\begin{tabular}{|lllll|}
\hline $\begin{array}{l}\text { Harris hip score } \\
(\mathbf{p = 0 . 2 5 6 )}\end{array}$ & $\begin{array}{l}\text { Group bipolar } \\
(\mathbf{n = 2 5})\end{array}$ & \multicolumn{2}{l|}{$\begin{array}{l}\text { Group AMP } \\
(\mathbf{n = 2 6})\end{array}$} \\
\hline No & $\mathbf{\%}$ & No & \% \\
\hline Failure (less 60) & 2 & 9.52 & 2 & 9.09 \\
\hline Poor (60-69) & 0 & 0.0 & 3 & 13.63 \\
\hline Fair (70-79) & 1 & 4.76 & 5 & 22.72 \\
\hline Good (80-89) & 9 & 42.85 & 5 & 22.72 \\
\hline $\begin{array}{l}\text { Excellent } \\
(\mathbf{9 0 - 1 0 0 )}\end{array}$ & 9 & 42.85 & 7 & 31.81 \\
\hline Total & 21 & 100.0 & 22 & 100.0 \\
\hline Mean \pm SD & $86.31 \pm 12.1$ & $79.86 \pm 15.42$ \\
\hline Not recorded & 4 & 16 & 4 & 15.38 \\
\hline
\end{tabular}

\section{Radiological assessment}

At the end of 1 year all the patients' radiographs was taken for the assessment and changes were recorded. We noticed one case of stem loosening in bipolar group, 2 cases of acetabular erosion and 1 case of heterotrophic ossification in the AMP group.
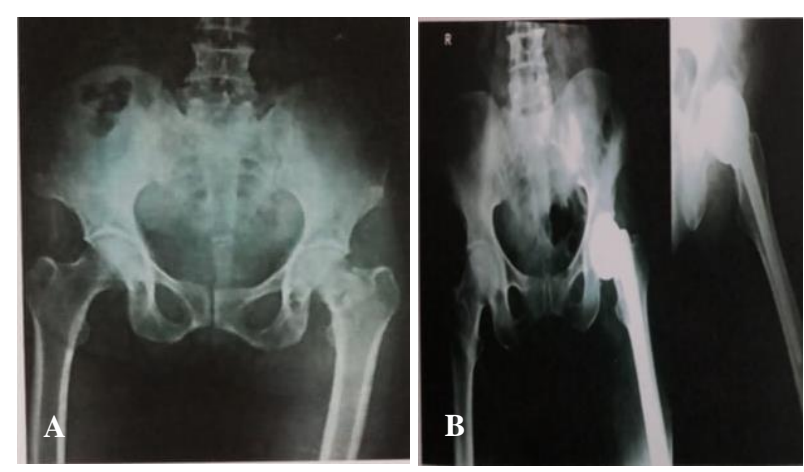

Figure 1: (A and B) Preoperative and follow up X-ray (AMP case).

\section{Complications}

Out of all cases, 1 case $(4.54 \%)$ in AMP group presented with posterior dislocation on $7^{\text {th }}$ postoperative day, for which closed reduction was done under GA and immobilized for one and half month and thereafter mobilized successfully. The dislocated hemiarthroplasties have a lower centre edge angle of Wiberg and the patients with low offset hips were more inherently unstable and hence prone to dislocation. ${ }^{12}$

One case $(4.54 \%)$ of AMP presented with periprosthetic fracture after 3 months following trauma, which was managed by open reduction and internal fixation with plate and screw retaining the same prosthesis. Two cases $(9.09 \%)$ from AMP presented with acetabular erosion and painful hip.
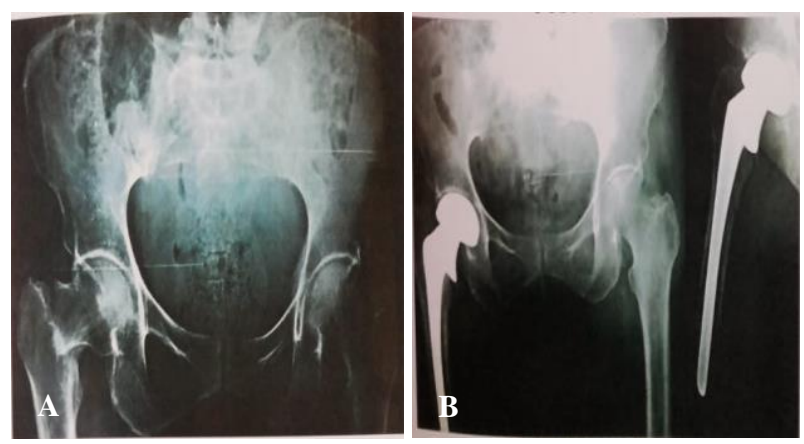

Figure 2: (A and B) Preoperative and follow up X-ray (uncemented bipolar case).

\section{DISCUSSION}

\section{Age distribution}

The average age of our patients was 64.2 years in case of bipolar group and 63.6 years in case of AMP group. Majority of our patients were between 60-70 years. Other authors in their study report similar age distribution

\section{Sex incidence}

The elderly females are more prone to fracture neck of femur as reported by Butler and others in their series. ${ }^{13}$ Hinton, Smith in their study showed the association of age, race and sex with the location of proximal femoral fractures in the elderly. ${ }^{14}$

\section{Type of fracture}

All the fractures in our series belonged to displaced fractures of Garden type 2 and 3. We could group 18 patients $(35.29 \%)$ into type 2 and 17 patients $(33.23 \%)$ into type 3 . The types of displacement (gardens III \& IV) are not taken as the criteria to choose the procedure for the management of fracture neck of femur. The age of the patient was considered by Arwade in their study. ${ }^{15}$ The time since fracture by Kulkarni are taken into consideration while selecting hemiarthroplasty for the management of fracture neck of femur in their study. ${ }^{16}$

\section{Mortality}

We had no operative deaths in our series. Totally 8 patients $(15.6 \%)$ expired during the follow up period of our series, 4 each from bipolar and AMP group. All the 
deaths were due to other medical co morbidities like IHD, diabetes, hypertension and stroke. $\mathrm{Su}$ et al reviewed the in-hospital mortality rates of patient's age greater than 65 years. They reported greater than 50,000 patients and found overall mortality rate of $5.6 \% .^{17}$

\section{Interval of postoperative stay}

In our series, all the patients were discharged after the patients were trained for active mobilization and when fit for discharge. Most of our patients, $65 \%$ of bipolar and $82.3 \%$ of AMP group stayed between 7-14 days. Cadler found that length of hospital stay was not significantly different for the two groups $(\mathrm{p}=0.40){ }^{18}$

\section{Pain comparison studies}

Sabnis et al in their study reported $52 \%$ of the patients in bipolar group and $66 \%$ of AMP group patients experienced pain. ${ }^{19}$ Whereas $55.1 \%$ of bipolar group and $53 \%$ of patients of uniploar group presented with pain in a study done by cadler. ${ }^{18}$

\section{Harris hip score comparison studies}

All the cases in our series were assessed according to this score and graded accordingly. We got $42.85 \%$ excellent result with bipolar group and $31.81 \%$ with AMP group. Distribution of result is statistically similar in both the groups $(p=0.256)$. The mean score is statistically more associated with bipolar group $(\mathrm{p}=0.182)$ (Table 5).

Table 5: Harris hip score comparison studies in other series.

\begin{tabular}{|llll|}
\hline Series & Year & $\begin{array}{l}\text { Bipolar } \\
(\%)\end{array}$ & $\begin{array}{l}\text { Unipolar } \\
(\%)\end{array}$ \\
\hline Carl Johan Hedbeck & 2010 & 79.3 & 70.4 \\
\hline Cadler & 1996 & 72 & 70 \\
\hline Nottage & 1990 & 85 & 77 \\
\hline Meyer & 1981 & 77 & 55 \\
\hline Drinker \& Murray & 1979 & 77.5 & 76.4 \\
\hline Our study & 2019 & 86.31 & 79.86 \\
\hline
\end{tabular}

In 2001, Davison et al presented the results from the same study for the 187 patients aged 65-79 years with a minimum of two year follow up. No differences between randomization groups were reported, but the interpretation is limited by the fact that $18 \%$ of the patients were lost to follow-up. ${ }^{20}$ According to Ong, there was no significant differences were found between the unipolar and bipolar groups. ${ }^{21}$

\section{Studies on unipolar prosthesis}

In 2003, Raia et al reported the results of a study including 115 patients randomized to a more modern cemented unipolar HA or bipolar HA with identical stems. At one year assessment there were no significant differences between the groups in terms of surgical complications and functional outcome. ${ }^{22}$

Wachtl et al and others in their series of unipolar hemiarthroplasty reported $1.2 \%$ dislocation rate, $0.6 \%$ protrusion and infection rate each in their study. ${ }^{23}$

Norrish and others in their series of unipolar hemiarthroplasty, reported $2 \%$ dislocation rate, $1.8 \%$ protrusion and $0.8 \%$ infection rate. They concluded $81 \%$ excellent or good result in their study cases of AMP. ${ }^{24}$

In a study of 140 elderly patients done by Naser et al found that fixed stem bipolar prosthesis is a superior option as compared to Austin Moore's prosthesis with better functional outcome, lower rate of complication and almost negligible cost difference. ${ }^{25}$ Functional activities like use of public transport were better with bipolar group. Complications like acetabular erosion were rare in bipolar group as comparison to AMP group. However, there has been a controversy regarding the use of cement for a long time.

So both the cemented and uncemented hemiarthroplasty are equally good options in the treatment of fracture neck of femur among elderly patients with minimal complications among the two methods. More data comparing uncemented and cemented hemiarthroplasty in patients with femoral neck fracture are still needed to substantiate their findings.

\section{CONCLUSION}

Based on the results of our study, we found there is a statistical difference between the two groups that is bipolar being better in functional aspects. On the other hand, incidence of complications was lower after the uncemented bipolar hemiarthroplasty, which in turn may indicate an advantage in the longer term. We conclude that uncemented bipolar hemiarthroplasry is a superior option as compared to Austin Moore's prosthesis with better functional outcome, Harris hip score and almost negligible cost difference. This is a study showing only early comparative results with a follow up of one year. A study with more number of patients and longer follow up is required to educate us better.

\section{ACKNOWLEDGEMENTS}

We thank our colleagues from Sri Siddhartha Academy of Higher Education who provided insight and expertise that greatly assisted the research. We thank faculty of Department of orthopaedics, Sri Siddhartha medical college, affiliated to Sri Siddhartha Academy of Higher Education for assistance and for comments that greatly improved the manuscript.

Funding: No funding sources

Conflict of interest: None declared

Ethical approval: The study was approved by the institutional ethics committee 


\section{REFERENCES}

1. Thorngren KG, Hommel A, Norrman PO, Thorngren J, Wingstrand $\mathrm{H}$. Epidemiology of femoral neck fractures. Injury. 2002;33(3):1-7.

2. Lu-Yao GL, Keller RB, Littenberg B, Weinberg JE. Outcomes after displaced fractures of the femoral neck. A meta-analysis of one hundred and six published reports. J Bone Joint Surg Am. 1994;76:15-25.

3. Van Vugt AB. The unsolved fracture. A prospective study of 224 consecutive cases with an intracapsular hip fracture. University of Nijmegen, Netherlands. Ref Type: Thesis/Dissertation, 1991.

4. Nicoll EA. The unsolved fracture. J Bone Joint Surg Br. 1963;45:239-41.

5. Rockwood CA, Jr, Green DP, Bucholz RW, Heckman JD. Fractures in adults. Philadelphia: Lippincott; 1996.

6. Moore AT, Bohlman HR. Metal Hip Joint: A Case Report. J Bone Joint Surg. 1943;25:688-92.

7. Harris WH. Traumatic arthritis of the hip after dislocation and acetabular fractures:treatment by mold arthroplasty. An end-result study using a new method of result evaluation. J Bone Joint Surg Am 1969;51:737-55.

8. Rosner B. Fundamentals of Biostatistics. 5th Edition. Duxbury; 2000: 80-240.

9. Riffenburg RH. Statistics in Medicine, second edition, Academic Press; 2005: 85-125.

10. Sunder Rao PS, Richard J. An Introduction to Biostatistics, A manual for students in health sciences, 4th edition. New Delhi: Prentice Hall of India; 2006: 86-160.

11. Suresh KP, Chandrasekhar S. Sample Size estimation and Power analysis for Clinical research studies. J Human Reprod Sci. 2012;5(1):7-13.

12. Ninh CC, Sethi A. Hip dislocation after modular unipolar Hemiarthroplasty. J Arthroplasty. 2009;24(5):768-75.

13. Butler M, Norton R, Lee-Joe T, Cheng A, Campbell AJ. The risk of hip fracture in older people from private homes and institutions. Age Ageing. 1996;25:381-5.

14. Hinton RY, Smith GS. The association of age, race and sex with the location of proximal femoral fractures in the elderly. J Bone Joint Surg. 1993;75:752-9.

15. Arvade DJ. A review of internal fixation and prosthetic replacement for fresh fractures of the femoral neck. Clini Orthop India. 1987;1:77-82.

16. Kulkarni GS. Pathology of fracture neck of the femur. Clin Orthop India. 1987;1:92-6.
17. Su H, Aharonoff GB, Hiebert R, Zuckerman JD, Koval KJ, et al. In hospital mortality after femoral neck fracture: do internal fixation and hemiarthroplasty differ? Am J Orthop. 2003;32:1515 .

18. Cadler SJ, Anderson GH, Jagger C, Harper WM, Gregg PJ. Unipolar or bipolar prosthesis for displaced intracapsular hip fracture in octogenarians: a randomized prospective study $\mathrm{J}$ Bone Joint Surg Br. 1996;78:391-4.

19. Sabnis BM, Brenkel IJ. Unipolar versus bipolar uncemented hemiarthroplasty for elderly patients with displaced intracapsular femoral neck fractures. J Orthop Surg. 2011;19(1):8-12

20. Davison JN, Cadler SJ, Anderson GH, Ward G, Jagger C, Harper WM, et al. Treatment for displaced intracapsular fracture of the proximal femur. A prospective randomized trial in patients aged 65 to 79 years. J Bone Joint Surg Br. 2001;83:206-12.

21. Ong BC, Maurer SG, Aharonaff GB, Zuckerman JD, Koval KJ. Unipolar versus bipolar hemiarthroplasty: functional outcome after femoral neck fracture at a minimum of thirty-six months of follow-up. J Orthop Trauma. 2002;16(5):317-22.

22. Raia FJ, Chapman CB, Herrera MF, Schweppe MW, Michelsen CB, Rosenwasser MP. Unipolar or bipolar hemiarthroplasty for femoral neck fractures in the elderly? Clin Orthop Relat Res 2003;414:25965.

23. Wacht SW, Jakob RP, Gautier E. Ten year patient and prosthesis survival after unipolar hip hemiarthroplasty in female patients over 70 years. J Arthroplasty. 2003;18(5):587-91.

24. Norrish AR, Rao J, Parker MJ. Prosthesis survivorship and clinical outcome of the Austin Moore hemiarthroplasty: an 8 year mean follow-up of a consecutive study of 500 patients. Injury. 2006;37(8):734-9.

25. Naser MA, Pathak R, Ahmad A. Superiority of fixed stem bipolar prosthesis over Austin Moore prosthetic in fracture neck femur. Int J Res Orthop. 2018;4:577-81.

Cite this article as: Veeranna HD, Ravi KB, Kumar KA. Surgical management of intracapsular fracture neck femur by hemiarthroplasty between uncemented bipolar prosthesis and Austin Moore's prosthesis: a comparative study in elderly population. Int J Res Orthop 2019;5:612-8. 